\title{
Research Article \\ Effect of Annealing on Microstructure and Mechanical Properties of Magnetron Sputtered Cu Thin Films
}

\author{
Shiwen Du and Yongtang Li \\ School of Materials Science and Engineering, Shanxi Key Laboratory of Metallic Materials Forming Theory and Technology, \\ Taiyuan University of Science and Technology, Taiyuan 030024, China
}

Correspondence should be addressed to Shiwen Du; tykddsw@126.com

Received 11 December 2014; Revised 26 February 2015; Accepted 26 February 2015

Academic Editor: Filippo Giannazzo

Copyright (C) 2015 S. Du and Y. Li. This is an open access article distributed under the Creative Commons Attribution License, which permits unrestricted use, distribution, and reproduction in any medium, provided the original work is properly cited.

$\mathrm{Cu}$ thin films were deposited on Si substrates using direct current (DC) magnetron sputtering. Microstructure evolution and mechanical properties of $\mathrm{Cu}$ thin films with different annealing temperatures were investigated by atomic force microscopy (AFM), X-ray diffraction (XRD), and nanoindentation. The surface morphology, roughness, and grain size of the Cu films were characterized by AFM. The minimization of energy including surface energy, interface energy, and strain energy (elastic strain energy and plastic strain energy) controlled the microstructural evolution. A classical Hall-Petch relationship was exhibited between the yield stress and grain size. The residual stress depended on crystal orientation. The residual stress as-deposited was of tension and decreased with decreasing of (111) orientation. The ratio of texture coefficient of $(111) /(220)$ can be used as a merit for the state of residual stress.

\section{Introduction}

With the rapid change of materials systems and decreased feature size, thin film microstructure and mechanical properties have become critical parameters for microelectronics reliability [1]. Copper is an attractive interconnecting material for current Si ultralarge scale integrated (ULSI) device due to its low resistivity and superior resistance to electromigration [2-4]. Cu film has attracted great attention worldwide due to its potential applications in replacing Al-based interconnects on silicon chips.

According to research object, film structure can be divided into crystalline form, crystallographic structure, and surface structure. Microstructure of materials here mainly refers to crystal orientation and grain size. The electrical resistivity and mechanical properties of $\mathrm{Cu}$ films are important factors for its use as interconnecting material. Magnetron sputtering has become one of commonly used techniques for industrial deposition of thin films and coatings, due to its simplicity and reliability [5]. Generally, structure and electrical qualities of films strongly depend on the deposition process [6]. On the other hand, the postprocessing such as annealing can also change the microstructure and mechanical properties of the films $[7,8]$.

In sputter deposition, the nature of the substrate, the deposition temperature, the deposition pressure, and the vacuum quality are some of the parameters that influence the film properties. Properties such as stress, texture, and morphology are of key importance for predicting the reliability of thin film systems. The influence of the magnetron source operation mode (standard or self-sustained), as well as the type of power (DC, medium frequency, or pulsed DC) on the microstructure, and surface morphology of the copper thin films have been reported [5]. Sputtering DC power affected the structural features, electrical properties, and the nucleation and growth of $\mathrm{Cu}$ films during the initial stage of sputtering [6]. A comparative study of structural, electrical, and thermoelectric properties of nanocrystalline copper thin films deposited using anodic vacuum arc plasma deposition technique and DC magnetron sputtering was also conducted [9]. The effects of barrier layer and annealing temperature on texture variation, grain growth, and void formation of nanocrystalline $\mathrm{Cu}$ films were investigated [10]. The deposition pressure and the type and cleaning condition 
of substrate had important role on the film properties. The substrate type and the substrate surface condition had marked influences on the texture of as-deposited $\mathrm{Cu}$ films [11]. Cu films were deposited on $\mathrm{Si}(001)$ substrates under various Ar deposition pressure by radio frequency (RF) magnetron sputtering. The intensities of $\mathrm{Cu}$ peaks changed with the Ar pressure systematically. Strong correlations were observed between optical emission, electron temperature, and the microstructure of $\mathrm{Cu}$ films [12].

For $\mathrm{Cu}$ nanocrystalline films to be widely used, it is necessary to explore its microstructure and mechanical properties. The physical properties and microstructure of $\mathrm{Cu}$ films, such as mechanical properties, grain boundary, and crystallographic texture can significantly influence the work reliability in microelectronic devices [10]. Mechanical properties of thin films often differ from those of the bulk materials [13-16]. The physical dimensions of thin film materials are generally comparable to the characteristic microstructural length scales that strongly influence their mechanical properties [17]. In general, two different size dependencies determine the properties of a material. One is the dimension characteristic of the physical phenomenon involved. The other is some microstructural dimension. Microstructural evolution during elevated temperature annealing of sputter deposited copper $(\mathrm{Cu})$ films was investigated by electron backscatter diffraction (EBSD). Not only are the $\mathrm{Cu}$ film texture and grain size a function of film thickness, but also the fraction of twin boundaries present in the material is strongly dependent upon film thickness [18].

Generally, microstructure and mechanical properties of films depend on the deposition process and postproduction process such as annealing. However, most previous works have focused on the deposition process. As we know, physical properties of the sputtered films are controlled by its microstructure. In this paper, we report the microstructural evolution and mechanical properties of the magnetron sputtered $\mathrm{Cu}$ thin films with different thicknesses after annealing at several temperatures. Surface topography/roughness and grain size are measured by AFM. Residual stress (stresses that remain in the films after annealing) and textures of the $\mathrm{Cu}$ films are evaluated with X-ray diffraction. Furthermore, nanoindentation is also performed to study the mechanical properties of the $\mathrm{Cu}$ films, which include the hardness, yield stress (the stress at which a material begins to deform plastically), and elastic modulus. Discussions are made in terms of the mechanical properties with film microstructure.

\section{Experimental Details}

Three series of copper films were produced by magnetron sputtering deposition on commercial $\mathrm{Si}(100)$ single-crystal wafer whose thickness was $525 \pm 25 \mu \mathrm{m}$. Size of the copper target is $\Phi 60 \mathrm{~mm}, 3 \mathrm{~mm}$ thickness. The substrate temperature $T_{s}$ is $473 \mathrm{~K}$, and the substrate bias $U_{s}$ is grounded. Before sputtering, wafer was ultrasonically cleaned in high purity acetone. After vacuum drying, wafer was reserved in a dry cylinder for use. Copper thin films were deposited by a magnetron sputter coater (FJL560II). Copper target material purity was $99.99 \mathrm{wt} . \%$. Base vacuum pressure of the sputter coater was $2 \times 10^{-4} \mathrm{~Pa}$, and $99.9 \%$ argon was used as a working gas whose pressure was $1.5 \mathrm{~Pa}$. The distance between the sputter target and the $\mathrm{Si}$ wafer was $60 \mathrm{~mm}$. Sputtering voltage was $470 \mathrm{~V}$ and power was $36 \mathrm{~W}$. Thickness of the films is tested by SEM. Deposition rate is calculated by films thickness and deposition time. Different thickness films are deposited by controlling the deposition time. The deposition time was 60,90 , and $170 \mathrm{~min}$, respectively, and these samples were labeled as A, B, and C accordingly. The film thickness was measured by S- 4800 field emission scanning electron microscope (SEM). For samples A, B, and C, thickness was $1.0 \mu \mathrm{m}, 1.6 \mu \mathrm{m}$, and $3.0 \mu \mathrm{m}$ accordingly. Some samples were annealed in vacuum at 300,400 , and $500^{\circ} \mathrm{C}$, respectively. The base pressure during annealing is $4 \times 10^{-4} \mathrm{~Pa}$.

Agilent 5420 atomic force microscope (AFM) was used to observe the sample surface morphology. Each sample was scanned at three different regions and then the typical region was utilized for analysis. Grazing incidence X-ray diffraction (GIXRD) was performed to study the texture in the annealed $\mathrm{Cu}$ films. Experiment was performed using the Philips X'Pert Pro XRD system with $0.5^{\circ}$ grazing incidence. The stresses of film specimens have been studied by the $\sin ^{2} \psi$. The mechanical properties of the annealed copper films were evaluated using a nanoindenter with a Berkovich tip [19]. The continuous stiffness modulation (CSM) technique was used, wherein the contact stiffness was measured continuously as a function of displacement under the load.

\section{Results and Discussion}

3.1. Surface Characterization by AFM. The representative AFM images of the coating samples with different thickness and after annealing at $300^{\circ} \mathrm{C}$ are shown in Figure 1. All the samples have a columnar surface morphology. The images of the $\mathrm{Cu}$ films were acquired in a $1 \mu \mathrm{m} \times 1 \mu \mathrm{m}$ area. It is clear that as the annealing temperature increased, the surface morphology evolved and the grains grew larger in the $\mathrm{Cu}$ films.

$S_{q}$ is the root mean square (RMS) height of the surface which is a statistical amplitude parameter representing the root mean square of surface roughness deviation from reference datum. It can be seen from Table 1 that the lowest $S_{q}$ value is observed for the samples annealed at $400^{\circ} \mathrm{C}$. The roughness decreases when continuous and compact films with crystal structure are formed during the films deposited. When the annealing temperature exceeds $400^{\circ} \mathrm{C}$, recrystallization occurs. Due to agglomeration and coalescence of the grains, the roughness of $\mathrm{Cu}$ film surface increases.

The grain growth in the $\mathrm{Cu}$ films can be correlated to the annealing temperature as shown in Table 2, using the grain size data determined by AFM. The driving force for grain growth in thin films materials is the reduction of grain boundary energy that results from the reduction of the total grain boundary area. In grain growth, some grains already present in the matrix grow at the expense of the other grains. A few grains which consume the surrounding (stagnant) fine-grained matrix will grow until the large grains meet and the fine-grained matrix is completely consumed [19-22]. 


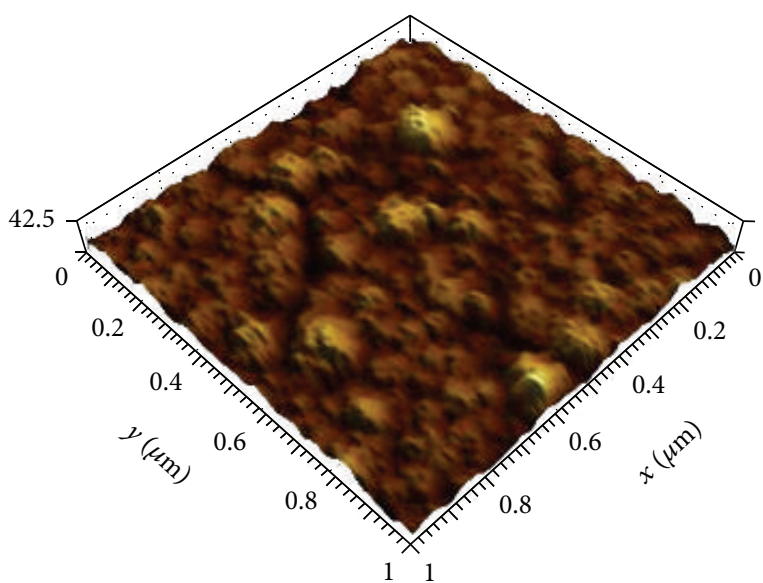

(a)

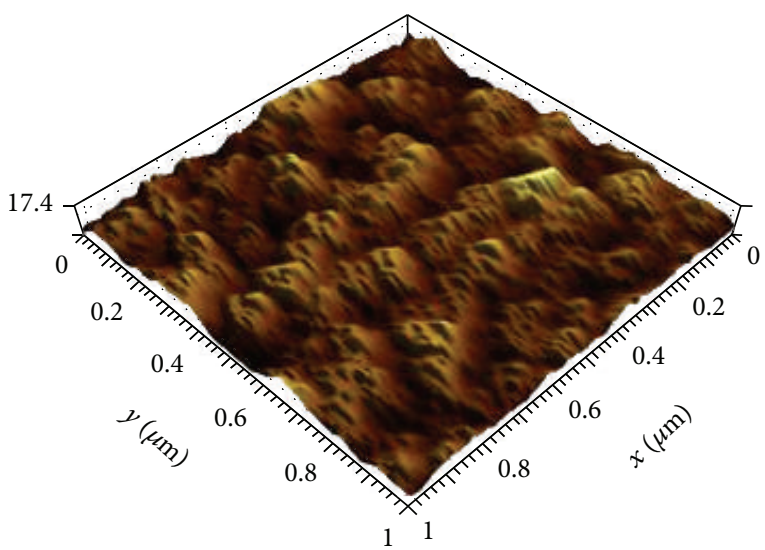

(c)

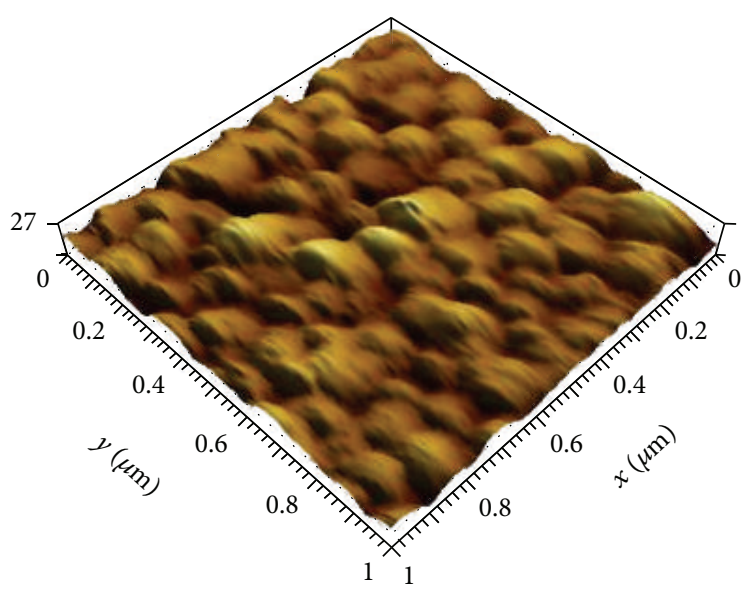

(e)

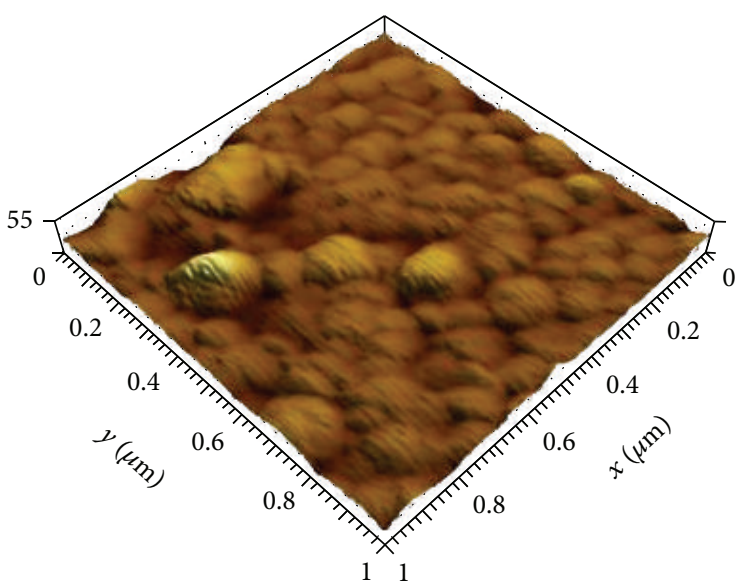

(b)

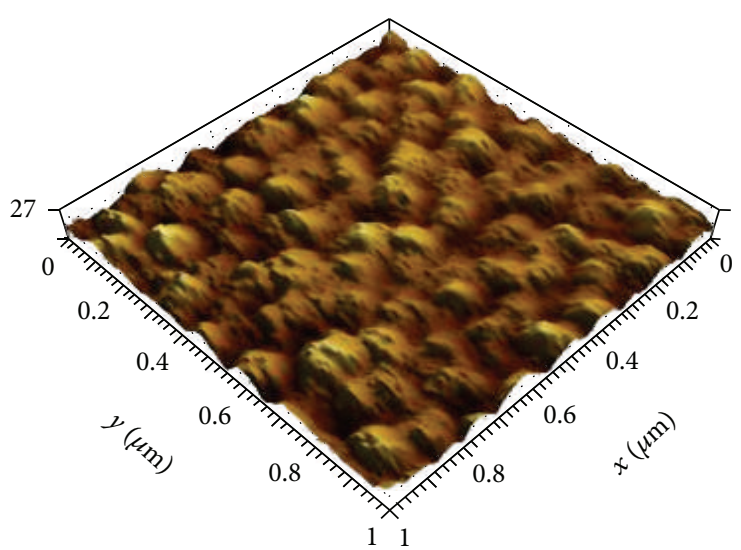

(d)

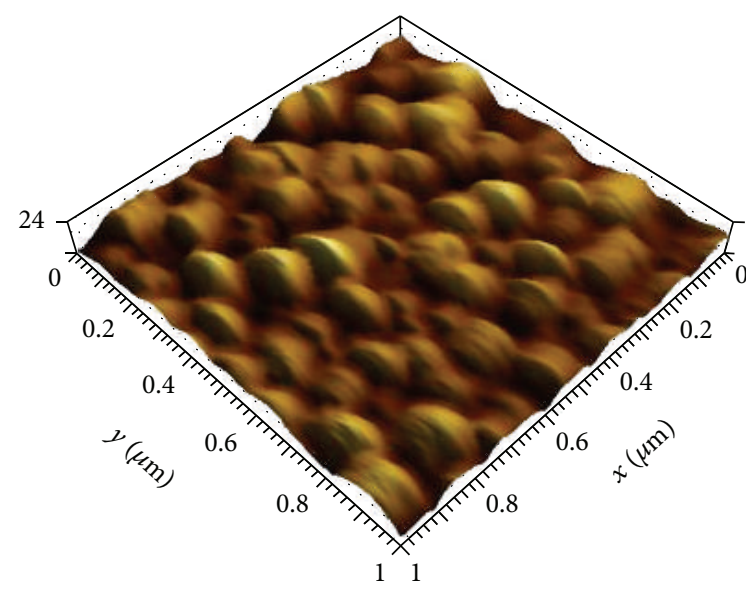

(f)

FIGURE 1: 3D surface topographies of the $\mathrm{Cu}$ films: (a) $1.0 \mu \mathrm{m}$ thick, as-deposited; (b) $1.0 \mu \mathrm{m}$ thick, annealed at $300^{\circ} \mathrm{C}$; (c) $1.6 \mu \mathrm{m}$ thick, asdeposited; (d) $1.6 \mu \mathrm{m}$ thick, annealed at $300^{\circ} \mathrm{C}$; (e) $3.0 \mu \mathrm{m}$ thick, as-deposited; and (f) $3.0 \mu \mathrm{m}$ thick, annealed at $300^{\circ} \mathrm{C}$.

The higher the annealing temperature is, the larger the grain growth driving force is. If the annealing temperature exceeds $400^{\circ} \mathrm{C}$, grains grow quickly and coalescence happens, which will cause grain boundary groove deepening and film agglomeration to occur.
3.2. Texture and Microstructure. Texture in materials has a large influence on many properties of thin films. XRD has been the primary method for the characterization of film texture for many years. The texture coefficient (TC) represents the texture of a particular plane, whose deviation 
TABLE 1: Surface roughness Sq (nm) for the $\mathrm{Cu}$ films with different thicknesses annealing temperatures.

\begin{tabular}{lccc}
\hline Annealing temperature $\left({ }^{\circ} \mathrm{C}\right)$ & \multicolumn{3}{c}{ Thickness $(\mu \mathrm{m})$} \\
& 1.0 & 1.6 & 3.0 \\
\hline As-deposited & 3.88 & 3.4 & 2.98 \\
300 & 3.66 & 3.09 & 2.61 \\
400 & 1.63 & 2.91 & 2.16 \\
500 & 2.88 & 4.08 & 9.48 \\
\hline
\end{tabular}

TABLE 2: Grain size $d(\mathrm{~nm})$ for the $\mathrm{Cu}$ films with different thicknesses and annealing temperatures.

\begin{tabular}{lccc}
\hline Annealing temperature $\left({ }^{\circ} \mathrm{C}\right)$ & \multicolumn{3}{c}{ Thickness $(\mu \mathrm{m})$} \\
& 1.0 & 1.6 & 3.0 \\
\hline As-deposited & 66 & 88 & 91 \\
300 & 100 & 124 & 143 \\
400 & 120 & 165 & 170 \\
500 & 375 & 405 & 550 \\
\hline
\end{tabular}

from the ideal value implies the preferred growth. Quantitative information concerning the preferential crystallite orientation was obtained from the texture coefficient $\mathrm{TC}_{h k l}$ defined as [23]

$$
\mathrm{TC}_{h k l}=\frac{I_{(h k l)} / I_{0(h k l)}}{\sum_{i=1}^{n} I_{(h k l)} / I_{0(h k l)}} \times 100 \%,
$$

where $I_{(h k l)}$ is the measured relative intensity of a plane $(h k l)$ and $I_{0(h k l)}$ is the standard intensity of the plane $(h k l)$ taken from the JCPDS data. The value $\mathrm{TC}_{h k l}=1 / n=0.25$ (i.e., $n=4$ for our case, as four planes are included in our XRD study) represents films with randomly oriented crystallites, while higher values indicate the abundance of grains oriented in a given $(h k l)$ direction [23].

3.2.1. Effect of Thickness on Texture. From Figures 2 and 3, we can see that the preferred orientation and texture in the thin films change with the thickness. The strongest X-ray reflections are visible from $\mathrm{Cu}(111)$ planes. This indicates that the crystallization occurs preferentially in the (111) planes. While the polycrystalline films are thin, growth of grain with (111) texture is favored by surface and interface energy minimization, especially in very thin films $[24,25]$. With the increase of the thickness, the (111) orientation decreases whereas the (220) orientation increases. Strain energy (the energy stored by a system undergoing deformation including elastic strain energy and plastic strain energy) controls the grain growth gradually as the thickness increases. Elastic strain energy is the potential mechanical energy stored in the configuration of a material as work is performed to distort its volume or shape. Plastic strain energy is the energy stored by a system undergoing plastic deformation.

3.2.2. Effect of Annealing Temperatures on Texture. Figure 4 shows the XRD patterns of the $\mathrm{Cu}$ films with a thickness of $1.0 \mu \mathrm{m}$ under different annealing temperatures. All

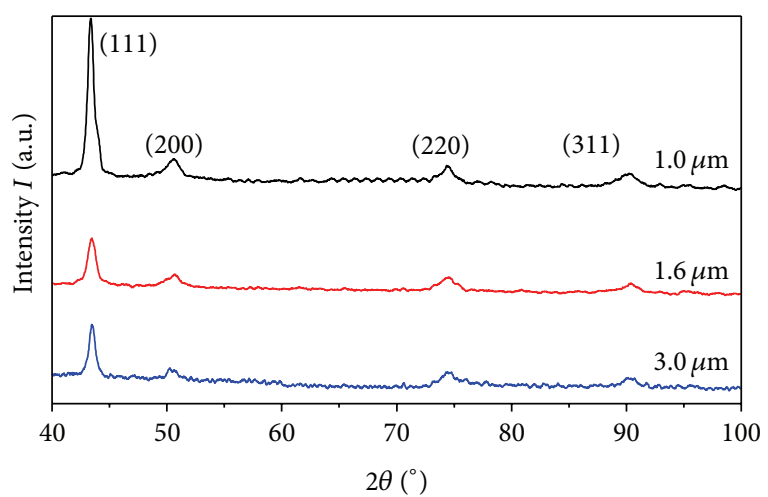

FIGURE 2: XRD patterns of the Cu films with different thicknesses.

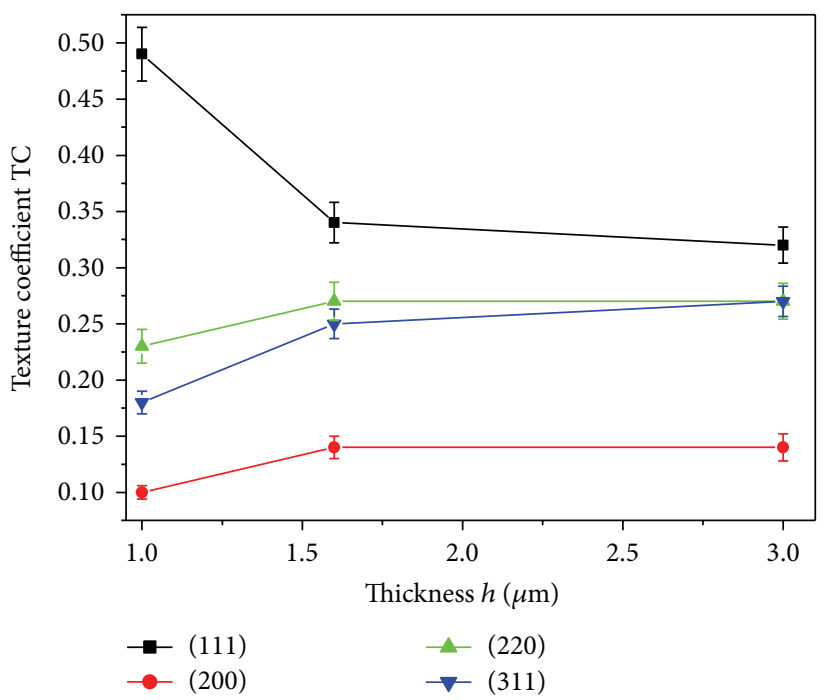

FIGURE 3: Texture coefficients of the $\mathrm{Cu}$ films with different thicknesses.

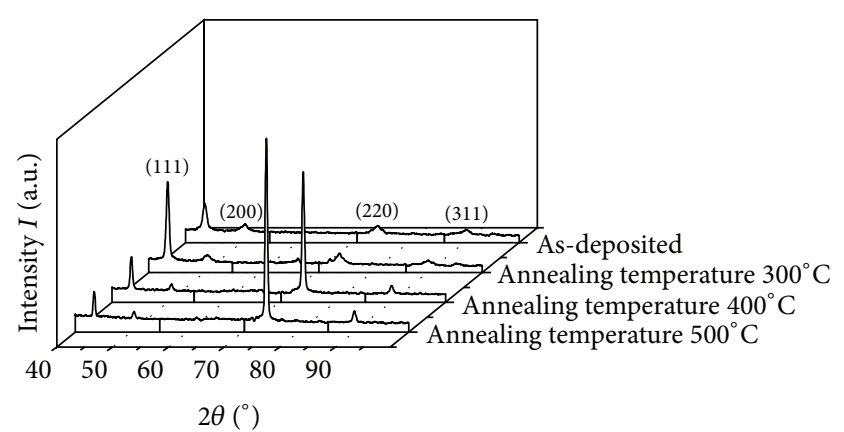

FIGURE 4: XRD patterns of the $1.0 \mu \mathrm{m} \mathrm{Cu}$ film annealed at different temperatures.

the films exhibit X-ray reflections from $\mathrm{Cu}$ (111), (200), (220), and (311). To investigate the evolution of crystallite orientations with different annealing temperatures, the texture coefficient under different annealing temperatures is shown in Figures 5-7 for the films with thickness of 1.0, 1.6, and $3.0 \mu \mathrm{m}$, respectively. 


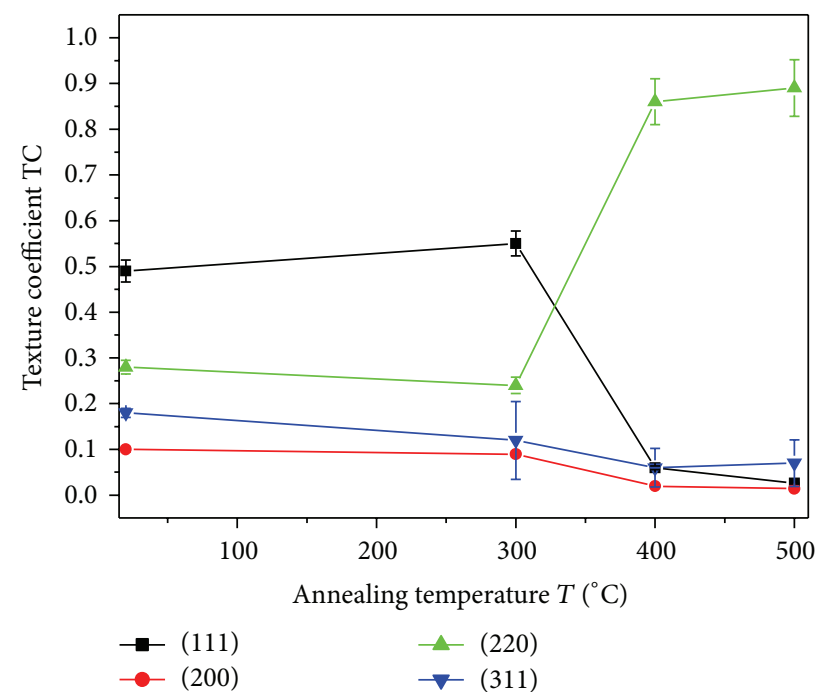

Figure 5: Texture coefficients of the $1.0 \mu \mathrm{m} \mathrm{Cu}$ film annealed at different temperatures.

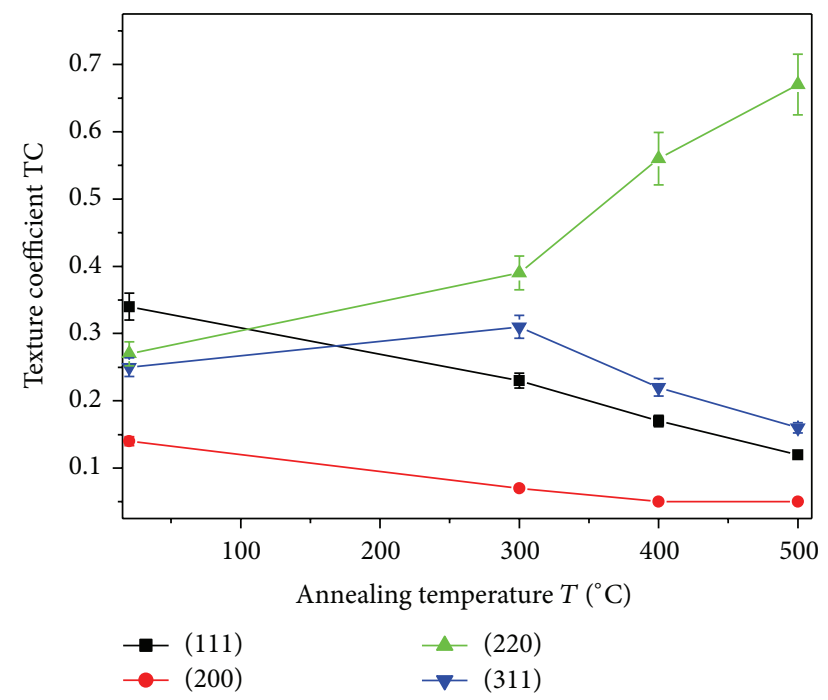

Figure 6: Texture coefficients of the $1.6 \mu \mathrm{m} \mathrm{Cu}$ film annealed at different temperatures.

The main driving force for subsequent grain growth is minimum total free energy (surface energy, grain interface energy, and film strain energy) [21]. For thinner films, grain growth is under the control of surface energy minimization. Only a few grains can grow whose surface energy is relatively lower than the others. Grains whose surface energy is higher will be merged into adjacent grains. Grain growth eliminates free surface and thus the total surface energy decreases accordingly. However, for thicker films, grain growth is under the control of strain energy minimization. For face-centered cubic (fcc) metals, grain orientation which has the lowest plastic strain energy is the (220) plane [24]. Development of strain energy minimizing textures does not minimize surface and interface energies $[25,26]$. Therefore, surface structure of the copper films with different thicknesses reflects

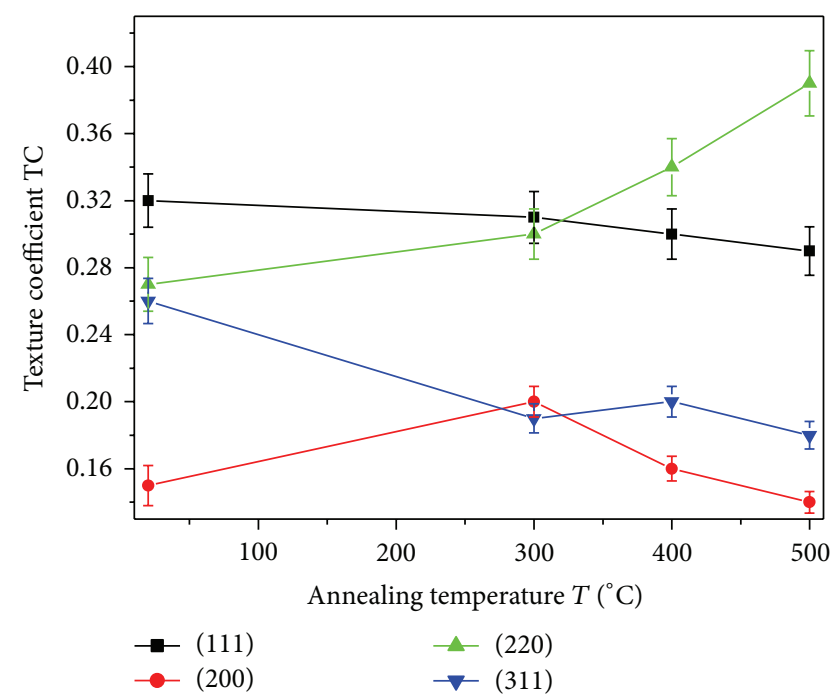

Figure 7: Texture coefficients of the $3.0 \mu \mathrm{m} \mathrm{Cu}$ film annealed at different temperatures.

a dynamic equilibrium between surface energy and strain energy. Surface energy is very important for the structure of thinner films, whereas strain energy is very important for the structure of thicker films.

During the annealing processes, the intensity of the (220) grain increases but that of the (111) grain decreases. A preferred grain orientation (220) after annealing is observed while (111) is the preferred orientation before annealing. The effect of yield in grain is proposed to explain the (220) preferred orientation during annealing. When the annealing temperatures increase, thin films will start to yield. Also, the minimum strain energy will control the grain growth. Inplane stress in a grain is a function of grain orientation factor $C_{i j k}$, and the yield stress of the grain also varies depending on its orientation. The orientation factor $C_{i j k}$ of (220) has the smallest one of 1.42 while that of (111) has the largest one of 3.46 [27]. When the thin films start to yield, for grains of equal initial sizes, the (220) grains will yield before the (111) grains; thus, the (220) grains have an energetic advantage for further growth [28]. This yielding process also leads to strain energy minimization. This may explain why the (220) grains grow faster than other grains and become the final preferred orientation.

In addition, initial grain size also has an effect on the texture evolution. With a certain volume, the smaller and the more uniform the grain is, the more evenly the strain energy will disperse to all the grain. So the distribution of internal stress (the stress due to difference in the thermal expansion coefficients and thickness between films and substrates during annealing) will be more even which will make the grain with minimization strain energy grow easily and quickly. Grain size in thin films is smaller than thick films. We can see from Figures 5-7 that the finial texture coefficient after annealing at $500^{\circ} \mathrm{C}$ in thick films is less than thin films.

3.3. Mechanical Properties. Nanoindentation was performed on all the $\mathrm{Cu}$ films annealed at different temperatures. 
The typical load-indentation depth curves for the $3.0 \mu \mathrm{m}$ film annealed at different annealing temperatures are shown in Figure 8. It can be seen from Figure 8 that the load/unload curves for all the samples are nearly similar, which may be attributed to the similar crystalline nature of $\mathrm{Cu}$ films. Figure 9 shows the hardness as a function of the annealing temperature for the $\mathrm{Cu}$ films with various thicknesses. More recent and systematic experiments indicate that both the grain size and the film thickness have a marked influence on the strength of thin films [29-32]. Relationship between the hardness and the yield stress can be expressed as $H=3 \sigma_{y} . \sigma_{y}$ is the yield stress and $H$ is the hardness.

Effect of different parts of microstructure on the yield stress can be expressed as [29]

$$
\sigma_{y}=\sigma_{0}+k d^{-n}+k^{\prime} t^{-m}
$$

where $\sigma_{0}$ is the bulk yield stress (large-grained polycrystal); $k d^{-n}$ is the contribution from the grain boundaries ( $d$, grain size); $k^{\prime} t^{-m}$ is the contribution from the film surface or interface ( $t$, film thickness). The first two terms together form the well-known Hall-Petch relation, where $n=0.5$ commonly. Combining the data in Table 2 and Figure 9, Figure 10 can be obtained, which shows that the grain size dependence of strength in $\mathrm{Cu}$ thin films on $\mathrm{Si}$ substrates followed a Hall-Petch type relation. This is the described Hall-Petch effect that establishes a linear dependency of the hardness with the reciprocal square root of grain size. Clearly, the strengthening of the sputtered copper films was mainly attained by grain refinement. The Hall-Petch effect is explained in terms of a restriction in the movement of grains, that is, strengthening due to the formation of pileups in the larger grain boundaries associated with low grain size. From Figure 8, we can see that the indentation depth increases with the annealing temperatures under the same load which may be a factor affecting the Hall-Petch type relation. In addition, grain size changes with the films thickness, which may be another reason for the yield stress variation.

Different load-indentation depth curves for the $\mathrm{Cu}$ films annealed at different temperatures imply different indentation plastic characteristics for these films. These curves can be separated into the following three stages: pure elastic deformation stage at the beginning of the load; elasticplastic deformation stage after displacement jump; and elastic response during unload. It agrees with the Hertz contact theory well during the elastic deformation stage. The lower the annealing is, the less the elastic displacement is. Displacement jump caused by the dislocation pileup and increment on the plastic deformation region increase with the increase of the grain size. With the decrease of the grain size, the density of the grain boundaries increases. It cannot only act as the source of dislocation but also decrease the dislocation activation energy.

The values of elastic modulus can also be obtained by nanoindentation. The Young modulus decreased $20 \%$ compared to that of the traditional coarse-grained $\mathrm{Cu}$. The elastic modulus is one of the intrinsic properties of a material [33]. Elastic modulus is an important indicator to reflect the bond strength between the atoms. Many factors can affect

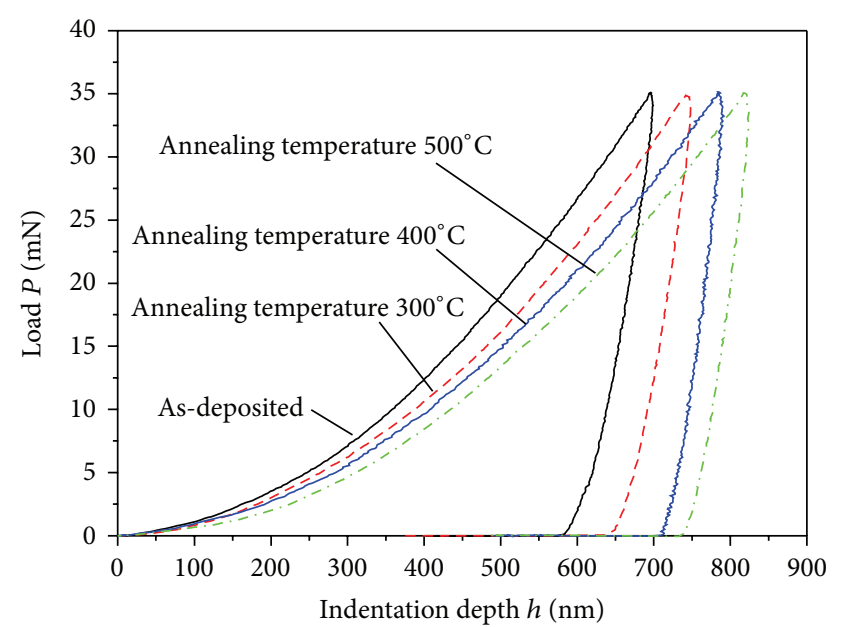

FIgURE 8: Load-indentation depth curves for the $3.0 \mu \mathrm{m} \mathrm{Cu}$ films annealed at different temperatures.

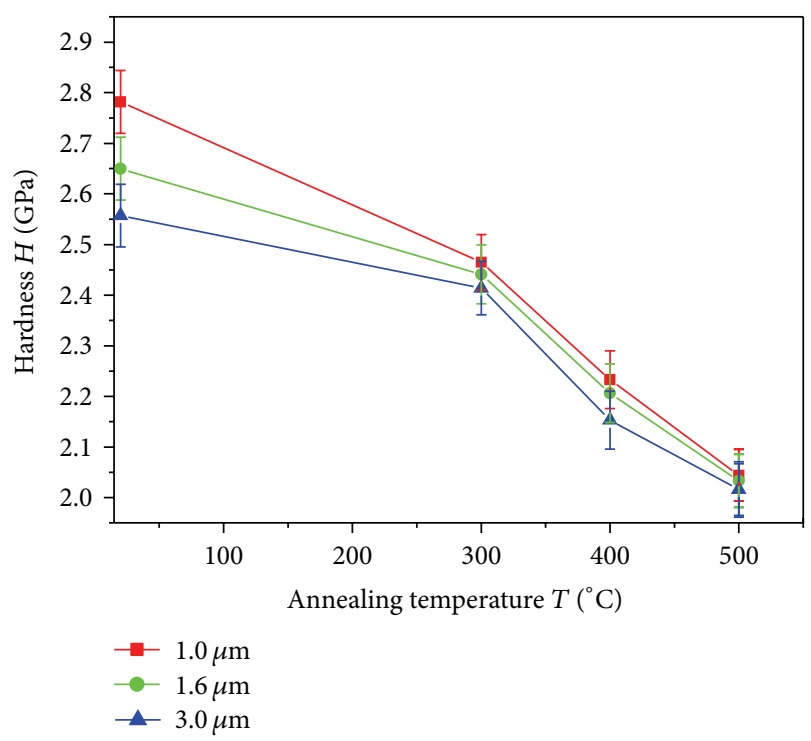

Figure 9: Hardness versus annealing temperature for the $\mathrm{Cu}$ films with different thicknesses.

the elastic modulus such as texture [33], grain coalescence, and microcrack [34]. Elastic modulus of the Cu thin films will decrease $20 \%$ when $1 / 3$ of grain boundaries is destroyed based on the microcrack mechanism.

XRD diffraction technique was carried out to investigate the residual stress by the well-know $\sin ^{2} \Psi$ method. Figure 11 shows the relationship between residual stress and TC(111)/TC(220) ratio in Cu films. The film with (111)orientated grains had the highest tensile one and that with (220)-orientated grains had the lowest tensile one. The residual stress in as-deposited copper films reached a high value but decreased down to a minimum value after samples annealing. This was obviously due to the thermal relaxation of residual stresses and the annealing effect on microstructure defects. This may be due to the preferred growth of grains, which leads to a change of residual stress. 


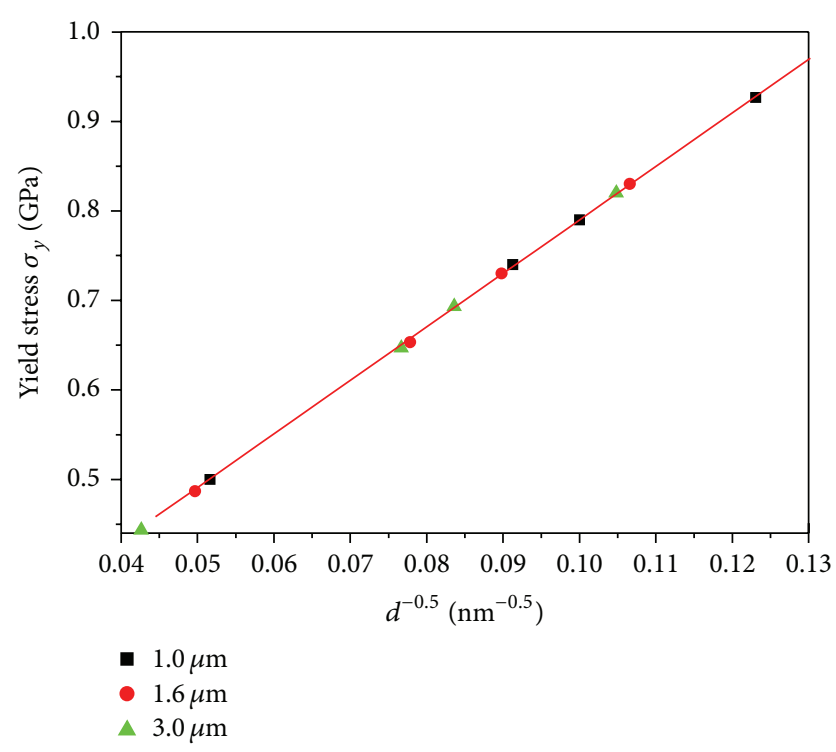

Figure 10: Trend of yield stress dependency on grain size for the $\mathrm{Cu}$ films.

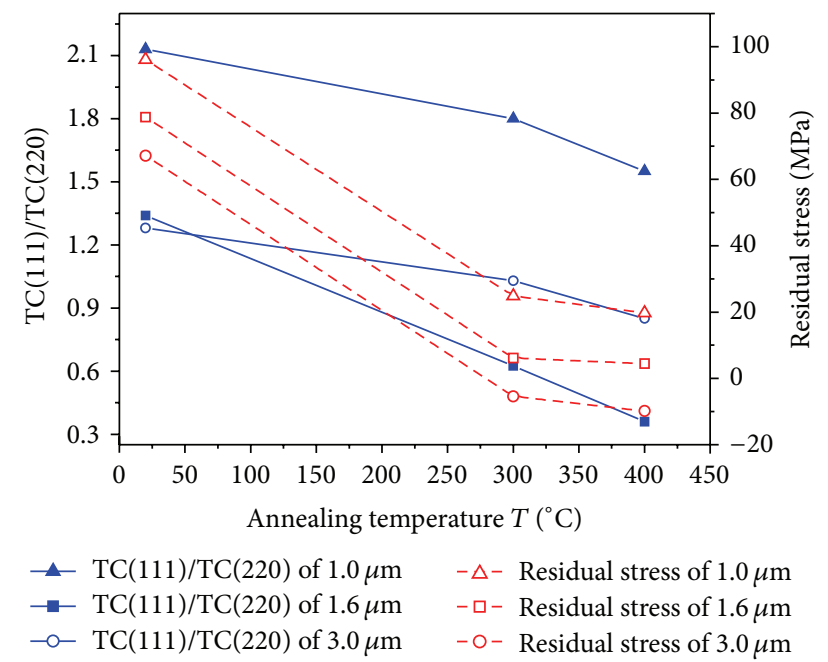

FIGURE 11: TC(111)/TC(220) ratio and residual stress versus annealing temperatures of $1.0 \mu \mathrm{m}, 1.6 \mu \mathrm{m}$, and $3.0 \mu \mathrm{m}$.

\section{Conclusions}

The effect of annealing treatment on magnetron sputtered $\mathrm{Cu}$ films is investigated using AFM, XRD, and nanoindentation techniques. Surface topography and microstructural evolution after annealing is studied in detail. Relationship between the microstructure and the mechanical properties of the thin films is also proposed. The higher the texture of (111) is, the lower the resistivity is. With the increase of (111) texture, tensile stress increases. For microelectronic application, large residual stress will cause cavity, crack, and peeling of $\mathrm{Cu}$ films which will cause circuit deformation and even produce short circuit or open circuit. Annealing is usually taken during IC. Although the resistivity of $\mathrm{Cu}$ films decreased a little, the reliability of the system is greatly increased.
The following are our main conclusions.

(1) Annealing treatment can provide enough energy for the grain to grow. When the annealing temperature is less than $400^{\circ} \mathrm{C}$, the higher the annealing temperature is, the more the energy for the grain growth will be. With the grain growth, surface void is filled and the surface RMS decreases. However, when the annealing temperature is $>400^{\circ} \mathrm{C}$, grain grows abnormally and coalescence occurs. Surface void defects and microcracks increase and the surface RMS increases.

(2) Films thickness, grain size, and annealing temperatures are the main factors that affect the microstructure of the annealed $\mathrm{Cu}$ films. The minimization of energy including surface energy, interface energy, and strain energy (elastic strain energy and plastic strain energy) controls the microstructural evolution.

(3) The grain size dependence of strength in the $\mathrm{Cu}$ thin films on the Si substrates followed a Hall-Petch type relation. In addition, grain size changes with the films thickness, which may be another reason for the yield stress variation. The as-deposited $\mathrm{Cu}$ films are in tensile state and have strong (111) orientation. During the annealing, with the decreasing of (111) orientation, tensile stress decreased. The ratio of TC(111)/TC(220) can be used as a merit for the state of residual stress.

\section{Conflict of Interests}

The authors declare that there is no conflict of interests regarding the publication of this paper.

\section{Acknowledgments}

This project is supported by National Basic Research Development Program of China (973 Program, Grant no. 2009 CB724200), Research Fund for the Doctoral Program of Higher Education of China (Grant no. 20111415120002), and Shanxi Provincial Science Foundation for Youths of China (Grant no. 2010021023-4).

\section{References}

[1] A. A. Volinsky, J. Vella, I. S. Adhihetty et al., "Microstructure and mechanical properties of electroplated $\mathrm{Cu}$ thin films," in Proceedings of the Materials Research Society Symposium, vol. 649, pp. Q 5.3.1-Q 5.3.6, Boston, Mass, USA, November 2001.

[2] S. P. Murarka, "Multilevel interconnections for ULSI and GSI era," Materials Science and Engineering R: Reports, vol. 19, no. 3-4, pp. 87-151, 1997.

[3] S. P. Murarka, R. J. Gutmann, A. E. Kaloyeros, and W. A. Lanford, "Advanced multilayer metallization schemes with copper as interconnection metal," Thin Solid Films, vol. 236, no. 1-2, pp. 257-266, 1993.

[4] R. W. Vook, "Electrical control of surface electromigration damage," Thin Solid Films, vol. 305, no. 1-2, pp. 286-291, 1997.

[5] A. Wiatrowski, W. M. Posadowski, G. Jóźwiak, J. Serafińczuk, R. Szeloch, and T. Gotszalk, "Standard and self-sustained magnetron sputtering deposited $\mathrm{Cu}$ films investigated by means 
of AFM and XRD," Microelectronics Reliability, vol. 51, no. 7, pp. 1203-1206, 2011.

[6] M.-T. Le, Y.-U. Sohn, J.-W. Lim, and G.-S. Choi, "Effect of sputtering power on the nucleation and growth of $\mathrm{Cu}$ films deposited by magnetron sputtering," Materials Transactions, vol. 51, no. 1, pp. 116-120, 2010.

[7] A. K. Siker, A. Kumar, P. Shukla, P. B. Zantye, and M. Sanganaria, "Effect of multistep annealing on mechanical and surface properties of electroplated $\mathrm{Cu}$ thin films," Journal of Electronic Materials, vol. 32, no. 10, pp. 1028-1033, 2003.

[8] P. Shukla, A. K. Sikder, P. B. Zantye, A. Kumar, and M. Sanganaria, "Effect of annealing on the structural, mechanical and tribological properties of electroplated $\mathrm{Cu}$ thin films," Materials Research Society Symposium Proceedings, vol. 182, pp. F3.16.1-F3.16.7, 2004.

[9] S. K. Mukherjee, L. Joshi, and P. K. Barhai, "A comparative study of nanocrystalline $\mathrm{Cu}$ film deposited using anodic vacuum arc and dc magnetron sputtering," Surface \& Coatings Technology, vol. 205, no. 19, pp. 4582-4595, 2011.

[10] Z. H. Cao, H. M. Lu, and X. K. Meng, "Barrier layer and annealing temperature dependent microstructure evolution of nanocrystalline $\mathrm{Cu}$ films," Materials Chemistry and Physics, vol. 117, no. 1, pp. 321-325, 2009.

[11] B. Okolo, P. Lamparter, U. Welzel, T. Wagner, and E. J. Mittemeijer, "The effect of deposition parameters and substrate surface condition on texture, morphology and stress in magnetronsputter-deposited Cu thin films," Thin Solid Films, vol. 474, no. 1-2, pp. 50-63, 2005.

[12] Q. X. Zhao, F. Bian, Y. Zhou et al., "Optical emission, electron temperature, and microstructure of $\mathrm{Cu}$ film prepared by magnetron sputtering," Materials Letters, vol. 62, no. 25, pp. 41404142, 2008.

[13] W. D. Nix, J. R. Greer, G. Feng, and E. T. Lilleodden, "Deformation at the nanometer and micrometer length scales: effects of strain gradients and dislocation starvation," Thin Solid Films, vol. 515, no. 6, pp. 3152-3157, 2007.

[14] Z. P. Bažant, Z. Guo, H. D. Espinosa, Y. Zhu, and B. Peng, "Epitaxially influenced boundary layer model for size effect in thin metallic films," Journal of Applied Physics, vol. 97, no. 7, Article ID 073506, 2005.

[15] H. D. Espinosa, M. Panico, S. Berbenni, and K. W. Schwarz, "Discrete dislocation dynamics simulations to interpret plasticity size and surface effects in freestanding FCC thin films," International Journal of Plasticity, vol. 22, no. 11, pp. 2091-2117, 2006.

[16] D. S. Gianola, S. van Petegem, M. Legros, S. Brandstetter, H. van Swygenhoven, and K. J. Hemker, "Stress-assisted discontinuous grain growth and its effect on the deformation behavior of nanocrystalline aluminum thin films," Acta Materialia, vol. 54, no. 8, pp. 2253-2263, 2006.

[17] E. Arzt, "Size effects in materials due to microstructural and dimensional constraints: a comparative review," Acta Materialia, vol. 46, no. 16, pp. 5611-5626, 1998.

[18] N.-J. Park, D. P. Field, M. M. Nowell, and P. R. Besser, "Effect of film thickness on the evolution of annealing texture in sputtered copper films," Journal of Electronic Materials, vol. 34, no. 12, pp. 1500-1508, 2005.

[19] G. M. Pharr, "Measurement of mechanical properties by ultralow load indentation," Materials Science and Engineering A, vol. 253, no. 1-2, pp. 151-159, 1998.

[20] J.-M. Zhang, K.-W. Xu, and V. Ji, “Competition between surface and strain energy during grain growth in free-standing and attached $\mathrm{Ag}$ and $\mathrm{Cu}$ films on Si substrates," Applied Surface Science, vol. 187, no. 1-2, pp. 60-67, 2002.

[21] V. Weihnacht and W. Brückner, "Abnormal grain growth in 111 textured Cu thin films," Thin Solid Films, vol. 418, no. 2, pp. 136$144,2002$.

[22] C. V. Thompson and R. Carel, "Texture development in polycrystalline thin films," Materials Science and Engineering B, vol. 32, no. 3, pp. 211-219, 1995.

[23] C. S. Barret and T. B. Massalski, Structure of Metals, Pergamon Press, Oxford, UK, 1980.

[24] J.-M. Zhang, K.-W. Xu, and M.-R. Zhang, “Theory of abnormal grain growth in thin films and analysis of energy anisotropy," Acta Physica Sinica, vol. 52, no. 5, pp. 1207-1211, 2003.

[25] H. L. Wei, H. Huang, C. H. Woo, R. K. Zheng, G. H. Wen, and X. $\mathrm{X}$. Zhang, "Development of $\langle 110\rangle$ texture in copper thin films," Applied Physics Letters, vol. 80, no. 13, pp. 2290-2292, 2002.

[26] R. Carel, C. V. Thompson, and H. J. Frost, "Computer simulation of strain energy effects vs surface and interface energy effects on grain growth in thin films," Acta Materialia, vol. 44, no. 6, pp. 2479-2494, 1996.

[27] J. E. Sanchez Jr. and E. Arzt, "Effects of grain orientation on hillock formation and grain growth in aluminum films on silicon substrates," Scripta Metallurgica et Materiala, vol. 27, no. 3, pp. 285-290, 1992.

[28] F. Spaepen, "Substrate curvature resulting from the capillary forces of a liquid drop," Journal of the Mechanics and Physics of Solids, vol. 44, no. 5, pp. 675-681, 1996.

[29] Y.-J. Choi and S. Suresh, "Size effects on the mechanical properties of thin polycrystalline metal films on substrates," Acta Materialia, vol. 50, no. 7, pp. 1881-1893, 2002.

[30] M. A. Meyers, A. Mishra, and D. J. Benson, "Mechanical properties of nanocrystalline materials," Progress in Materials Science, vol. 51, no. 4, pp. 427-556, 2006.

[31] D. Y. W. Yu and F. Spaepen, "The yield strength of thin copper films on Kapton," Journal of Applied Physics, vol. 95, no. 6, pp. 2991-2997, 2004.

[32] W. D. Nix and H. Gao, "Indentation size effects in crystalline materials: a law for strain gradient plasticity," Journal of the Mechanics and Physics of Solids, vol. 46, no. 3, pp. 411-425, 1998.

[33] S. H. Hong, K. S. Kim, Y.-M. Kim, J.-H. Hahn, C.-S. Lee, and J.-H. Park, "Characterization of elastic moduli of $\mathrm{Cu}$ thin films using nanoindentation technique," Composites Science and Technology, vol. 65, no. 9, pp. 1401-1408, 2005.

[34] N. R. Shamsutdinov, A. J. Böttger, and B. J. Thijsse, "Grain coalescence and its effect on stress and elasticity in nanocrystalline metal films," Acta Materialia, vol. 55, no. 3, pp. 777-784, 2007. 

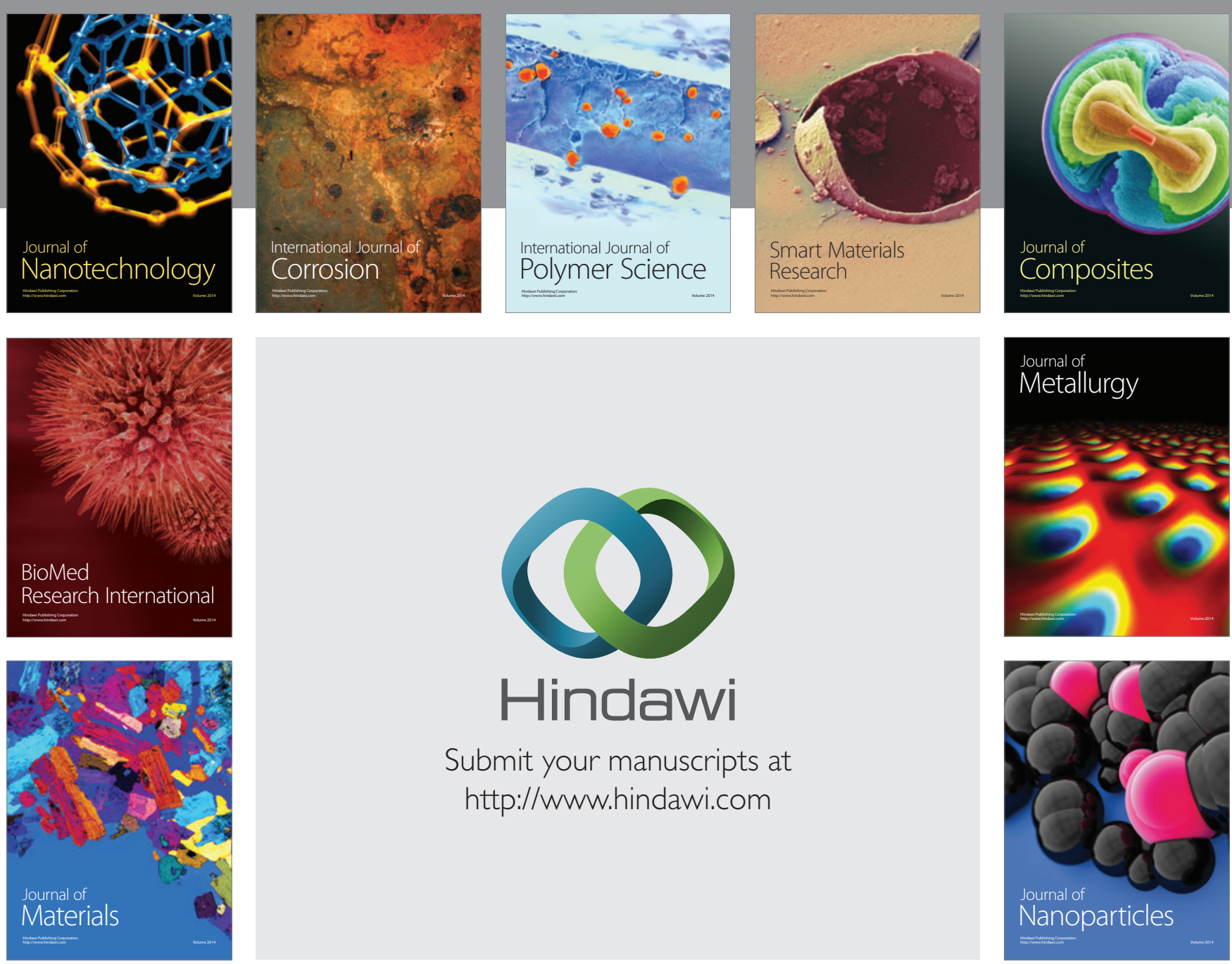

Submit your manuscripts at http://www.hindawi.com
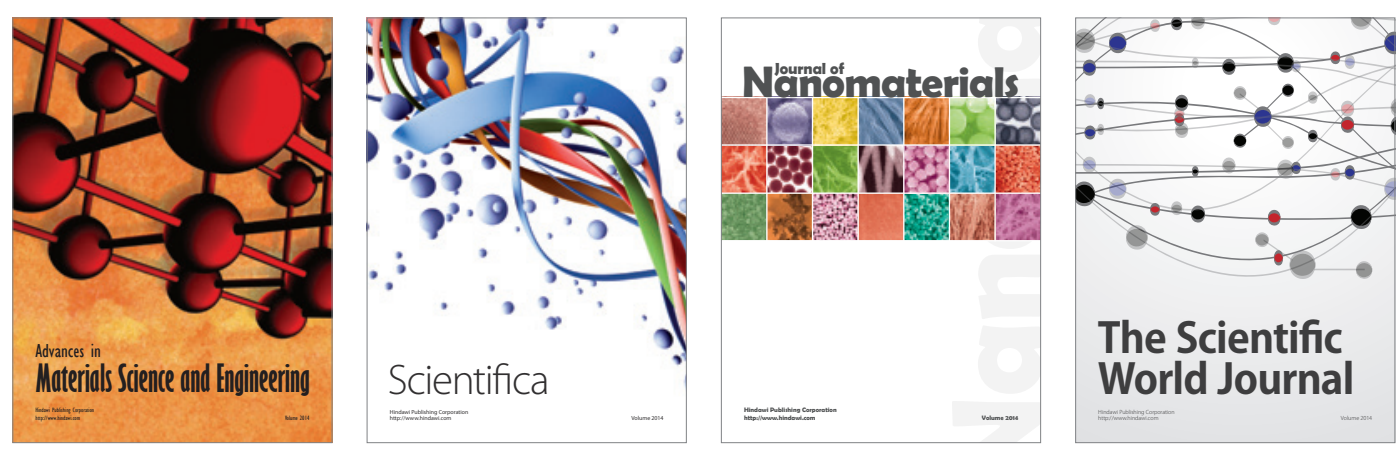

\section{The Scientific World Journal}
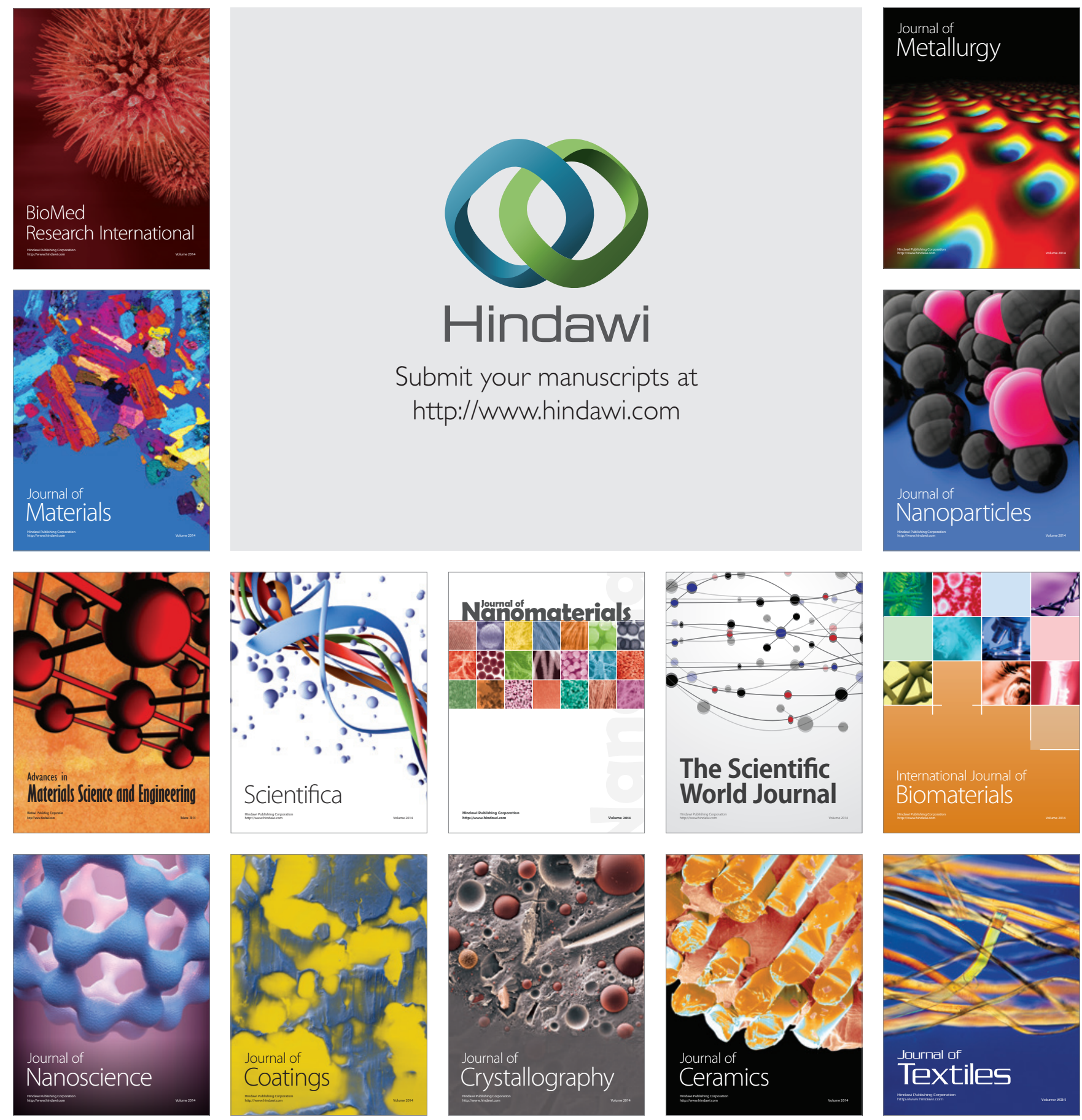